\title{
Role of School Teachers in Pupils' Mental Health Promotion
}

Aya M. Abd El Latif1, Maha Mohamed El Gaafary1, Menan Abdel Maksoud Rabie2,Hanan Said Ez Elarab1.

${ }^{1}$ Community, Environmental and Occupational Medicine department, ${ }^{2}$ Psychiatry department,Faculty of Medicine,Ain Shams University.

Received :February 2016Accepted : April 2016

\begin{abstract}
Background: Mental health is an integral and essential component of health.School teachers should have an effective role in promoting mental health of their students. Objective: To investigate teachers' attitude towards their role in pupils' mental health promotion, and identify barriers they may encounter.Methods:Multistage random sampling was undertaken, where Misr El Gededa and El Nozha Educational Zones were selected randomly from education zones in Cairo governorate. Twenty two (22)schools were selected from different strata of governmental, experimental and private schools in the preparatory stage for boys and girls. All available school teachers were invited to complete a self-administered questionnaire including questions aboutpersonal characteristics, work related qualifications andteachers' cognitive, affective and behavior attitude towards pupils mental health promotion. Results:382 teachers (95.5\%) agreed that teachers play an influential role in recognizing pupils with mental health problems, 389 teacher $(97.25 \%)$ agreed that referring pupils with mental health problems for appropriate early support reduces their risk of developing mental health problems, 374 $(93.5 \%)$ agreed that schools hold a unique position in positively affecting the mental health of pupils and nearly 350 teachers $(88 \%)$ reported inadequatetrainingto recognize the earlysigns of pupils'mental healthproblems, concerns over workload and lack of services that promote teachers mental health to mitigate the workload before expecting from them to promote pupils' mental health as barriers to pupils mental health promotion. Total scores of the three dimensions of attitude (cognitive, affective and behavioral) were as regard the following variables the two educational zones, different school types, educational stages, graduation college, and taking educational diploma among those graduated from college other than graduation college, attending activities about pupils` mental health,teaching for special needs pupils and teaching for pupils with mentalhealth problems.Conclusion:Most of teachers had positive attitude toward their role in pupils mental health promotion. Recommendation:Implementation of a training program for teachers on a screening tool to pick up cases that need specialized help and activation of the role of teachers in participation in health promoting activities with their pupils.
\end{abstract}

Keywords: mental health promotion,teachers'role, attitude.

Corresponding author:Aya M. Abd El Latif Email: Drayahmostafa789@yahoo.com

\section{Introduction:}

Mental health is an integral and essential component of health. Mental health promotion involves actions to create living conditions and environments that support mental health and allow people to adopt and maintain healthy lifestyles ${ }^{1}$. Children mental health promotion is a critical issue across the globe. Some 31 percent of the world's population is aged under $18^{2}$ of those, around 10 percent,220 million children and young people have 
a diagnosable mental disorder (mainly anxiety, depression or conduct disorder). Of all child morbidity, 23 percent are mental rather than physical ill-health ${ }^{3,4,5}$.

In the national survey of 14,271 Egyptian children and adolescents (aged 10-18 years), 59\% reported experiencing feelings of fear or anxiety ${ }^{6}$ In Egyptian surveys (a sample of 8459 school children aged 6-12 years) anxiety disorders were diagnosed in $7.9 \%$, hyperkinetic disorder in $2.2 \%$ and nocturnal enuresis was present in $1.9 \%$ of children ${ }^{7}$.In a governorate-wide study involving a representative sample of primary and preparatory schools in the city of Alexandria $10.3 \%$ of pupils demonstrated depressive scores. In another study on a sample of patients from the child psychiatry outpatient clinic at the Institute of Psychiatry of Ain Shams University hospitals diagnoses were as follows: $28 \%$ attention-deficit hyperactivity disorder (ADHD); 24\% mental retardation; $17 \%$ autism; $17 \%$ conduct disorder; and $18 \%$ childhood depression, anxiety, or schizophrenia. 14\%had nocturnal enuresis. $24 \%$ of patients with ADHD were referred by school teachers. ${ }^{8}$

In 2013, the World Health Assembly approved a "Comprehensive Mental Health Action Plan for 2013-2020". The Plan is a commitment by all WHO's Member States to take specific actions to improve mental health, one of the objectives of the action plan is to implement strategies for promotion and prevention in mental health. Actions that should be taken to reach this objective are to lead and coordinate multi-sectoral strategy that combines universal and targeted interventions for promoting mental health and preventing mental disorders; reducing stigmatization, discrimination and human rights violation; and which is responsive to specific vulnerable groups across the life span and integrated into the national mental health and health promotion strategies. One of the options for implementation of these actions is to develop school based promotion and prevention, including: life/skills programs,programs to counter bullying and violence, awareness raising of the benefits of a healthy life style and the risks of substance use; early detection and intervention for children and adolescents exhibiting emotional or behavioral problems. ${ }^{9}$

Teachers are in a very powerful position. Their behavior, as a model and their opinions as to what constitutes good mental health, impact very directly on the concepts of mental health adopted by their pupils. They are concerned in promoting some aspects of mental health, such as improving the self-esteem of their learners, teaching acceptable ways of relating to others and managing stress. ${ }^{5}$ Yet, teachers may be the most underused resources in mental health delivery. ${ }^{10}$.

Children mental health promotion cannot be achieved without proper attention to the role of teachers and their great impact on their pupils. ${ }^{11}$

The objective of the current study is to investigate teachers cognitive, affective and behavior attitude towards their role in pupils' mental health promotion and to identify barriers facing teachers in promoting pupils' mental health.

\section{Methods:}

A cross sectional studyhas been conducted during the academic year 2015 / 2016.

The target population was elementary (primary and preparatory) school teachers.

Multistage random sampling was undertaken, where Misr El Gededaand El Nozha Educational Zones were selected from a list of education zones 
in Cairo governorate. Then 22Schools were selected from different strataof governmental, experimental and private schools in the preparatory stage for boys and girls. All available school teachers were invited to complete aselfadministered questionnaire.

A modified self-administered questionnaire including questions about personal characteristics, work experience, and a set of questions assessing teachers'cognitive, affective and behavior attitude toward their role in pupils' mental health promotion usinganinventoryadapted from a study carried outin Kuwait 2012 about middle schoolteachers' attitudes and perceptions about their rolein promoting pupils' mental health. ${ }^{12}$ Togetherwith another questionnaire used by Daniszewskiin Canada 2013 about teachers' mental health literacy and capacity regarding pupils' mental health ${ }^{(13) .}$

A pilot study was done upon 28 teachers from Misr El GededaElnamozagia preparatory school.

Data Management and Analysis:The collected data were revised, coded, tabulated and introduced to a PC using Statistical package for Social Science (SPSS 20 for windows). Data cleaning and checking for quality and entry wereperformed. Data was presented and appropriate tests of significance wereapplied according to the type of data. Mean and standard deviation and t-test were used for testing differences in quantitative data and qualitative data were presented in frequencies and percentage and Chi- square test was used for measuring associations.

Administrative approvals were obtained from the managers of Central Agency for Public Mobilization and Statistics(CAPMAS), Ministry of education and the educational zones and confidentiality of the data was assured (anonymous questionnaire).
Ethical approval was obtained from faculty of Medicine Ain Shams University ethical committee.

\section{Results}

Table 1 shows that the majority of study participants were females 269 $(67.3 \%)$,their mean age was $43.02 \pm$ 8.62 years and $64.5 \%$ were between 35 50 years old. Mean years of teaching experience was $18.83 \pm 8.42$ years. $78.8 \%$ had work experience for more than 15 years. $55.4 \%$ were graduated from facultyof Education, $44.6 \%$ from other faculties.43\% were primary school teachers, $32.3 \%$ preparatory schoolteachers and $24.8 \%$ were teaching for both primary and preparatory stages. $38.5 \%$ were working at Arabic governmental schools $33.5 \%$ in experimental schools and $28 \%$ in private schools.

Table 2 shows that the mean score in the cognitive component of role of pupils' school teachers perception was $31 \pm 2.12$ (no. of items $=34$ ), the affective component was $7 \pm 1.68$ (no. of items $=10$ ) and in the behavioral component the average score was 19.46 \pm 2.64 (no. of items $=22$ ).

Table 3 shows that total cognitive score was statistically significant different in different school types(Arabic governmental, experimental and private schools), grade, past experience of teaching for special needs pupils and past experience of teaching for pupils with mental problems in regular classes. Total affective score was statistically significant different in the two educational zones, different school categories(Arabic governmental, experimental and private schools) and grade and total behavioral score was statistically significant higherin teachers with past experience of teaching for special needs pupils .

Table (4) shows that $97.25 \%$ of teachers, agreed that referring pupils 
with mental health problems for appropriate early support reduces their risk of developing mental health problems. $95.5 \%$ agreed that teachers play an influential role in recognizing pupils with mental health problems, while $89.5 \%$ agreed that it is not the teachers' job to promote pupils' mental health in the classroom and $25 \%$ of the 400 participating teachers agreed that having pupils with mental health problems in theirclass impedes the learning of other pupils.

Table (5) shows that $90 \%$ of the participating teachers were interested in recognizing pupils' mentalhealthproblems and $94.25 \%$ of them would feel happy topromotepupils' mental health and $44.25 \%$ would feel comfortable when managing a class that includes pupils with mental health problems.

Table (6) shows that although $89.5 \%$ agreed to carry on the responsibilityofpromotingpupils'

mental healthin their classroom, yet $66.75 \%$ of mentioned that they would suggest to the principle to move pupils with mental health issues to another class.

Table (7) shows that nearly 350 teachers $(88 \%) \quad$ reported inadequatetrainingto recognize the earlysigns of pupils'mental healthproblems, workload and lack of services that promote teachers' mental health and consequently improving pupils' mental health as barriers to pupils mental health promotion.

\section{Discussion}

The majority of the participating teachers in the study sample $(67.3 \%)$ were females (table 1), this is consistent with the last CAPMAS report for the academic year 2014/2015 that reported $60.9 \%$ of teachers working in the primary stage and $51.1 \%$ of teachers in the preparatory stage are females. ${ }^{14}$.
Results of the current study revealed that the majority of teachers had positive attitude toward their role in pupils mental health promotion.

Total scores of the three dimensions of attitude (cognitive, affective and behavioral) were as regard the following variables the two educational zones, different school types, educational stages, graduation college, and taking educational diploma among those graduated from college other than graduation college, attending activities about pupils' mental health, teaching for special needs pupils and teaching for pupils with mental health problems.

The average total cognitiveattitude score was significantlyaffected by the past experience of teaching for pupils with mental problems in regular classes, this finding is in line with Bryer\&Signorini, 2011 who found that teachers reported learning about mental health symptoms more from practical experience than from any university level course suggesting that classroom experience is the major source of knowledge for teachers in as regard pupils` mental health. ${ }^{15}$

Total affective attitude score is significantly different between private schools and both subtypes of governmental schools this mean that teachers in private schools were more comfortable dealing with pupils` mental health problems and more interested in pupils mental health problems these may be due to more suitable work conditions, less workload and number of pupils in the classroom. Total behavioral score was statistically significant different in teachers with past experience of teaching for special needs pupils. Previous experience with pupils with mental disorders could be a drive for those teachers to help more pupils with mental problems.

The current study findings revealed that teachers agree with that they have 
a role in promoting pupils' mental health and that this role is part of their responsibilities, $94.25 \%$ felt happy promoting pupils' mental health, also $89.5 \%$ agreed to accept responsibilityfor promotingpupils' mental healthin classroom. This is in line with the results showed by Reinke et al., 2011 that $89 \%$ of teachers agreed that schools should be involved in addressing the mental health needs of children and they perceived themselves as having primary responsibility in this field. ${ }^{16}$ However, $89.50 \%$ of teachers agreed that it's not their job to promote pupils' mental health in the classroomand they reported lack of awareness about teacher's role and responsibility regarding pupils' mental health and teachers' negative attitudes towards mental health issues as personal barriers to pupils 'mental health promotion $(87.75 \%$ and $74.5 \%$ respectively), these results refer to the contradiction in the teachers' response although they agreed that they have role in mental health promotion of pupils there is fear of this responsibility specially within the current educational system .This was evident in their responses to questions about institutional barriers as they agreed that workload (87.75\%)lack of services that promote teachers mental health to mitigate the workload before expecting from them to promote pupils' mental health $(87.50 \%)$, the current curriculum, pedagogy and the examination system( $87.25 \%)$ and limited class time (84\%) as barriers to pupils' mental health promotion .

Such a discrepancy had also been noted by Cohall et al. 2007, who found that however teachers approved the idea that they have an important role in pupils' mental health promotion; they feel less comfortable while dealing with pupils' mental health problems, as they feel insufficient prepared and supported to be a part in this responsibility. ${ }^{17}$. Similarly, Rothì et al. (2008) revealed that teachers felt that promoting pupils' mental health could be an extra burden and managing a classroom that include pupils with mental health problems is a common factor responsible for teachers' work related stress. ${ }^{18}$

Tamara D. Daniszewski , 2013 also stated that teachers participating in his study suggested that school-based mental health programs should focus initially on enhancing their own mental health before they should be expected to deliver such programs to their pupils. ${ }^{13}$

Most of teachers (91.5\%) believed that mental health problems are alterable problems and early identification of these problems has great impact on the outcomes of management as they agreed on the following statements: the majority of people who experience mental health problems can recover if they get help in an early stageand, mental health problems that are not recognized early can become more severe, and referring pupils with mental health problems for appropriate early support reduces their risk of developing mental health disorder with $91.5 \%$, $91 \%$ and $97.25 \%$ respectively. These results are approved by Han\& Weiss, 2005; Kirby \& Keon, 2006 that emphasized that utilizing teachers in the early identification of mental health problems of pupils has a powerful impact on youth recovery rates and overall improvement and also on the teacher's ability to manage the classroom. ${ }^{19,20}$

The majority of participating teachers believed that they have an role in recognizing pupils mental health problems as they agreed on the following statements: teachers play an influential role in recognizing pupils 
with mental health problems and teachers are expected to assume some responsibility in the early recognition of pupils' mental health problems with $95.50 \%, 90 \%$ respectively. Also $90 \%$ were interested in recognizing pupils' mental health problems. These results are in line with Rothì et al, 2008 who reported that teachers participated in their study believed they have a duty in identifying pupils who may have mental health problems. $^{18}$

On the other hand these results are in contrast to Reinke et al., 2011 as teachers in his study reported having a minimal role in conducting screening and behavior assessments for mental health issues in their pupils, believing this to be the primary responsibility of the school psychologist despite they perceived themselves as having primary responsibility for implementing classroom-based behavioral interventions. ${ }^{16}$

$87.75 \%$ identified inadequate training to recognize the early signs of pupils' mental health problems as a barrier to pupils mental health promotion. This result is similar to Bolton, 2002 who stated that about $75 \%$ of teachers need training about pupils` mental health issues specially recognizing pupils with problems, Repie,2006 who revealed that teachers reported lack of knowledge and training skills as the most significant barrier to identifying and recognizing pupils' mental health (21) and Koller\&Bertel, 2006 denoted that teachers receive little to no preservice training in the identification of children who present with mental health issues. ${ }^{22}$

However teachers reporting inadequate training as a barrier, only $68.50 \%$ were willing to engage into training that provide them with the appropriate skills to recognize and deal with pupils with mental health issues, such discrepancy can be explained in the light of previously discussed institutional barriers and the fact that $61.50 \%$ of teachers agreed that there is no existing educational policy which expects teachers to be responsible in promoting pupils' mental health.

Previous researches had shown that in order for teachers to recognize pupils with mental health issues, they need professional development in order to have the awareness, knowledge, skills, and resources to help their 23,24,25,26,27

The ministry of education had adopted the concept of inclusive education in all public schools (Arabic governmental and experimental schools) , $24.19 \%$ of teachers participating in the current study had past experience inteaching for pupils` with special needs from discussion with the teachers, teachers who are willing and cooperative assigned to classes that include these pupils. The findings also revealed that $78 \%$ of them had past experience in teaching for pupils with mental problems in regular classes. Reinke et al., 2011 had found that $75 \%$ of all of the participating teachers reported either working with or referring students with mental health issues over the past year. ${ }^{16}$

$25 \%$ of teachers in the current study agreed that havingpupils with mentalhealth problems in theirclass impedesthe learningof otherpupils, $66.75 \%$ of teachers had intended to suggest to the school administration to move pupils with mental health problems from their classes., only $44.25 \%$ feel comfortable managing a class that includes pupils with mental health problems, and $41.25 \%$ feel positive to havea pupil with mental health problems in their class, this can reflect the unpreparedness of teachers to deal with pupils neither with mental 
health disorders nor mental health problems .

The same situation was stated by Koller\&Bertel, 2006 as an outcome of the inclusion policy adopted by Canadian schools, general education teachers are faced with pupils who present with mental health problems . Yet, teachers are not equipped with fundamental knowledge about mental illness or preventiveskills that can help them performing their role in pupils' mental health promotion. ${ }^{22}$ In the teachers' responses, it is evident that they are not comfortable managing classes with pupils with mental health problems they might feel stressed and having low selfefficacy in their ability to manage the class. This was also concluded by Skaalvik\&Skaalvik, 2010 that teachers saw these as challenge and overload $^{27 .}$ Han \& Weiss, 2005 also revealed that many teachers were feeling helpless when it comes to helping pupils with mental health issues. ${ }^{19}$.

\section{Conclusion}

Most of teachers had positive attitude toward their role in pupils mental health promotion in the three components of attitude.

\section{Recommendation}

Implementation of a training program for teachers after a screening tool to pick up cases that need specialized help and activation of the role of teachers in participation in health promoting activities with their pupils.

\section{References}

1. World Health Organization (WHO) (2014). Mental health: strengthening our response. 2010.

Availableat:http://www.who.int/mediac entre/factsheets/fs220/en/ , last accessed 11/1/2017.
2. Aslam, A., Grojec, A., Little, C., Maloney, T., \& Tamagni, J. (2014). The State of the World's Children 2014 in Numbers: Every Child Counts. Revealing Disparities, Advancing Children's Rights. UNICEF. Available at www.unicef.org/sowc2014/umbers/, last accessed 11/1/2017.

3. World Health Organization (WHO)(2003). Caring for children and adolescents with mental disorders: setting WHO directions.

4. Lozano, R., Naghavi, M., Foreman, K., Lim, S., Shibuya, K., Aboyans, V., . . Ahn, S. Y. (2013). Global and regional mortality from 235 causes of death for 20 age groups in 1990 and 2010: a systematic analysis for the Global Burden of Disease Study 2010. The lancet, 380(9859), 2095-2128.

5. Herrman, H., Saxena, S., \& Moodie, R. (2005). Promoting mental health: concepts, emerging evidence, practice: a report of the World Health Organization, Department of Mental Health and Substance Abuse in collaboration with the Victorian Health Promotion Foundation and the University of Melbourne: World Health Organization.

6. Ibrahim, B., Sallam, S., El Tawila, S., El Gibaly, O., El Sahn, F., Lee, S., . . . Galal, O. (2000). Transitions to adulthood: a national survey of Egyptian adolescents.

7. Okasha, A., Lotaief, F., Ashour, A., El Mahalawy, N., Seif, e. D. A., \& ElKholy, G. (1999). The prevalence of obsessive compulsive symptoms in a sample of Egyptian psychiatric patients. L'Encephale, 26(4), 1-10.

8. Hussein, H., Shaker, N., El-Sheikh, M., \& Ramy, H. A. (2012). Pathways to child mental health services among patients in an urban clinical setting in Egypt. Psychiatric Services.Available at ' ps.psychiatryonline.org ' .last accessed 11/1/2017

9. WHO(2014):Mental health action plan 2013-2020. Available 
at:http://www.who.int/mental_health/p ublications/action_plan/en/ , last accessed 11/1/2017.

10. Lynn, C. J., McKay, M. M., \& Atkins, M. S. (2003). School social work: Meeting the mental health needs of pupils through collaboration with teachers. Children \& Schools, 25(4), 197-209.

11. Gowers, S., Thomas, S., \& Deeley, S. (2004). Can primary schools contribute effectively to tier I child mental health services? Clinical Child Psychology and Psychiatry, 9(3), 419425.

12. Alradaan, D. (2012). Middle school teachers'attitudes and perceptions about their role in promoting pupils'mental health in the state of kuwait.

13. Daniszewski, T. D. (2013).

Teachers' Mental Health Literacy and Capacity towards Pupil Mental Health. The University of Western Ontario.

14. Central Agency for Public Mobilization and Statistics (CAPMAS) (2016).Availableat:

http://www.capmas.gov.eg/Pages/Static

Pages.aspx?page_id=5035, last accessed 11/1/2017.

15. Bryer, F., \&Signorini, J. (2011). Primary pre-service teachers' understanding of students' internalising problems of mental health and wellbeing. Issues in Educational Research, 21(3), 233-258.

16. Reinke, W. M., Stormont, M., Herman, K. C., Puri, R., \& Goel, N. (2011). Supporting children's mental health in schools: Teacher perceptions of needs, roles, and barriers. School Psychology Quarterly, 26(1), 1.

17. Cohall, A. T., Cohall, R., Dye, B., Dini, S., Vaughan, R. D., \& Coots, S. (2007). Overheard in the halls: What adolescents are saying, and what teachers are hearing, about health issues. Journal of school health, 77(7), 344-350.
18. Rothì, D. M., Leavey, G., \& Best, R. (2008). On the front-line: Teachers as active observers of pupils' mental health. Teaching and Teacher Education, 24(5), 1217-1231.

19. Han, S. S., \& Weiss, B. (2005). Sustainability of teacher implementation of school-based mental health programs. Journal of abnormal child psychology, 33(6), 665-679.

20. Kirby, M., \& Keon, W. (2006). Out of the shadows at last: Highlights and recommendations of the final report on mental health, mental illness and addiction.

21. Repie, M. S. (2005). A school mental health issues survey from the perspective of regular and special education teachers, school counselors, and school psychologists. Education and Treatment of Children, 279-298.

22. Koller, J. R., \& Bertel, J. M. (2006). Responding to Today's Mental Health Needs of Children, Familes and Schools: Revisiting the Preservice Training and Preparation of SchoolBased Personnel. Education and treatment of children, 197-217.

23. Jorm, A. F., Kitchener, B. A., Sawyer, M. G., Scales, H., \& Cvetkovski, S. (2010). Mental health first aid training for high school teachers: a cluster randomized trial. BMC psychiatry, 10(1), 51.

24. Kirchner, J. E., Yoder, M. C., Kramer, T. L., Lindsey, M. S., \& Thrush, C. R. (2000). Development of an educational program to increase school personnel's awareness about child and adolescent depression. Education, 121(2), 235.

25. Langeveld, J., Joa, I., Larsen, T. K., Rennan, J. A., Cosmovici, E., \& Johannessen, J. O. (2011). Teachers' awareness for psychotic symptoms in secondary school: The effects of an early detection programme and information campaign. Early intervention in psychiatry, 5(2), 115121. 
26. Moor, S., Sharrock, G., Scott, J., McQueen, H., Wrate, R., Cowan, J., \& Blair, C. (2000). Evaluation of a teaching package designed to improve teachers' recognition of depressed pupils - a pilot study. Journal of adolescence, 23(3), 331-342.
27. Skaalvik, E. M., \& Skaalvik, S. (2010). Teacher self-efficacy and teacher burnout: A study of relations. Teaching and Teacher Education, 26(4), 1059-1069. 
Table (1): Characteristics, educational qualification of study participating teachers and school description $(\mathrm{N}=400)$

\begin{tabular}{|c|c|c|c|}
\hline \multicolumn{2}{|c|}{ Participant Characteristics } & no. & $\%$ \\
\hline \multirow{3}{*}{ Age group } & $<35$ years & 58 & 15.6 \\
\hline & $35-50$ years & 240 & 64.5 \\
\hline & $>50$ & 74 & 19.9 \\
\hline \multirow[t]{2}{*}{ Gender } & Male & 131 & 32.8 \\
\hline & Female & 269 & 67.3 \\
\hline \multirow{3}{*}{ Teaching to } & Male pupils & 40 & 10.0 \\
\hline & Female pupils & 52 & 13.0 \\
\hline & Both & 308 & 77.0 \\
\hline \multirow{3}{*}{$\begin{array}{l}\text { Teaching in which } \\
\text { educational level }\end{array}$} & Primary & 172 & 43.0 \\
\hline & Preparatory & 129 & 32.3 \\
\hline & Both & 99 & 24.8 \\
\hline \multirow[t]{2}{*}{ Educational zone } & El Nozha & 266 & 66.5 \\
\hline & MisrElgededa & 134 & 33.5 \\
\hline \multirow{3}{*}{ School category } & Governmental Arabic & 154 & 38.5 \\
\hline & Governmental experimental & 134 & 33.5 \\
\hline & Private & 112 & 28 \\
\hline
\end{tabular}

* prerequisite educational diploma is a 6 months training for those graduated from other non-educational faculties. $82.3 \%$ of 400 participating teachers were married, $11 \%$ single, $4.8 \%$ divorced and $2 \%$ widow. $93 \%$ of teachers who were ever married $(\mathrm{N}=356)$ had children.

Table (2): Mean and SD of cognitive, affective and behavioral

\begin{tabular}{|l|c|r|r|r|}
\hline & Total score & \multicolumn{1}{c|}{ Mean } & \multicolumn{1}{c|}{ SD } & \multicolumn{1}{c|}{ 95\% CI } \\
\hline Cognitive response & 34 & 31.00 & 2.196 & $30.78-31.22$ \\
\hline Affective response & 10 & 7.43 & 1.675 & $7.26-7.59$ \\
\hline Behavioral response & 22 & 19.46 & 2.639 & $19.20-19.72$ \\
\hline
\end{tabular}

$\mathrm{SD}=$ Standard Deviation. In each item agree $=2$, neutral $=1$, disagree $=0$ 
Table (3) : Comparison byTotal cognitive score, Total affective score and Total behavioral score

\begin{tabular}{|c|c|c|c|c|c|c|c|c|c|c|c|}
\hline & \multirow[b]{2}{*}{ Item } & \multirow[b]{2}{*}{$\mathbf{N}$} & \multicolumn{3}{|c|}{ Total cognitive score } & \multicolumn{3}{|c|}{ Total affective score } & \multicolumn{3}{|c|}{ Total behavioral score } \\
\hline & & & Mean & SD & $\begin{array}{c}\text { P- } \\
\text { value }\end{array}$ & Mean & SD & P-value & Mean & SD & $\begin{array}{c}\text { P- } \\
\text { value }\end{array}$ \\
\hline \multirow{3}{*}{$\begin{array}{l}\text { Educational } \\
\text { zone }\end{array}$} & Misr el gededa & 134 & 30.77 & 2.30 & \multirow[t]{3}{*}{0.135} & 7.79 & 1.87 & \multirow[t]{3}{*}{$0.004 *$} & 19.69 & 2.76 & 0.213 \\
\hline & El nozha & 266 & 31.12 & 2.13 & & 7.24 & 1.54 & & 19.35 & 2.57 & \\
\hline & private & 112 & 31.01 & 1.98 & & 7.03 & 1.44 & & 19.23 & 2.49 & \\
\hline \multirow[t]{3}{*}{ School type } & Govarabic & 154 & 31.36 & 2.12 & \multirow{3}{*}{$\begin{array}{l}0.009 \\
*\end{array}$} & 7.55 & 1.80 & \multirow[t]{3}{*}{$0.01 *$} & 19.45 & 2.63 & \multirow[t]{3}{*}{0.429} \\
\hline & Gov experimental & 134 & 30.57 & 2.39 & & 7.62 & 1.66 & & 19.67 & 2.77 & \\
\hline & private & 112 & 31.01 & 1.98 & & 7.03 & 1.44 & & 19.23 & 2.49 & \\
\hline \multirow{3}{*}{$\begin{array}{l}\text { Educational } \\
\text { Grade }\end{array}$} & primary & 172 & 31.10 & 2.13 & \multirow{3}{*}{$\begin{array}{l}0.004 \\
*\end{array}$} & 7.46 & 1.51 & \multirow[t]{3}{*}{0.281} & 19.33 & 2.57 & \multirow[t]{3}{*}{0.667} \\
\hline & preparatory & 129 & 31.33 & 1.90 & & 7.25 & 1.85 & & 19.56 & 2.51 & \\
\hline & Both & 99 & 30.38 & 2.54 & & 7.60 & 1.70 & & 19.58 & 2.92 & \\
\hline \multirow[t]{3}{*}{ Gender } & Male & 131 & 31.27 & 2.07 & \multirow[t]{3}{*}{0.081} & 7.32 & 1.72 & \multirow[t]{3}{*}{0.385} & 19.67 & 2.05 & \multirow[t]{3}{*}{0.269} \\
\hline & Female & 269 & 30.87 & 2.25 & & 7.48 & 1.65 & & 19.36 & 2.88 & \\
\hline & Girls & 52 & 31.10 & 2.14 & & 7.58 & 1.88 & & 19.63 & 2.79 & \\
\hline \multirow{5}{*}{$\begin{array}{l}\text { Graduation } \\
\text { college }\end{array}$} & Education & 206 & 31.00 & 2.24 & \multirow[t]{5}{*}{0.893} & 7.27 & 1.57 & \multirow[t]{5}{*}{0.893} & 19.36 & 2.75 & \multirow[t]{5}{*}{0.659} \\
\hline & Other & 166 & 30.96 & 2.20 & & 7.57 & 1.70 & & 19.48 & 2.54 & \\
\hline & other & 58 & 31.03 & 2.09 & & 7.43 & 1.74 & & 19.81 & 2.20 & \\
\hline & No & 69 & 31.04 & 2.11 & & 7.48 & 1.73 & & 19.51 & 2.34 & \\
\hline & No & 69 & 30.83 & 2.13 & & 7.10 & 1.86 & & 19.10 & 2.78 & \\
\hline \multirow{2}{*}{$\begin{array}{l}\text { Attending } \\
\text { activity } \\
\text { about } \\
\text { pupils` } \\
\text { mental } \\
\text { health }\end{array}$} & Yes & 143 & 31.07 & 2.23 & \multirow[b]{2}{*}{0.543} & 7.34 & 1.74 & \multirow[b]{2}{*}{0.543} & 19.37 & 2.74 & \multirow[b]{2}{*}{0.804} \\
\hline & No & 229 & 30.93 & 2.21 & & 7.44 & 1.57 & & 19.44 & 2.61 & \\
\hline \multirow{2}{*}{$\begin{array}{l}\text { Teaching } \\
\text { for special } \\
\text { needs } \\
\text { pupils }\end{array}$} & Yes & 90 & 31.41 & 2.06 & \multirow{2}{*}{$\begin{array}{c}0.034 \\
*\end{array}$} & 7.16 & 2.05 & \multirow{2}{*}{0.169} & 18.94 & 2.87 & \\
\hline & No & 282 & 30.84 & 2.25 & & 7.48 & 1.47 & & 19.56 & 2.57 & $0.05^{*}$ \\
\hline $\begin{array}{l}\text { Teaching } \\
\text { for pupils } \\
\text { with mental }\end{array}$ & Yes & 312 & 31.20 & 1.85 & & 7.44 & 1.57 & & 19.54 & 2.49 & \\
\hline $\begin{array}{l}\text { regular } \\
\text { classes }\end{array}$ & No & 88 & 30.31 & 3.03 & & 7.38 & 2.00 & & 19.19 & 3.12 & \\
\hline
\end{tabular}


Table (4) : Teachers' cognitive attitude to promoting pupils' mental health( $\mathrm{N}=400)$.

\begin{tabular}{|l|r|r|}
\hline \multicolumn{1}{|c|}{ Statement } & no & \% \\
\hline $\begin{array}{l}\text { Referring pupils with mental health problems for appropriate early } \\
\text { support reduces their risk of developing mental health problems. }\end{array}$ & 389 & 97.25 \\
\hline $\begin{array}{l}\text { Teachers playaninfluentialrole inrecognizingpupils with mental } \\
\text { health problems. }\end{array}$ & 382 & 95.50 \\
\hline $\begin{array}{l}\text { Themajorityof people whoexperience mental health problems can } \\
\text { recoverif they get helpearlyon. }\end{array}$ & 364 & 91.50 \\
\hline $\begin{array}{l}\text { Mentalhealthproblems thatare not recognized early can become more } \\
\text { severe. }\end{array}$ & 360 & 91.00 \\
\hline $\begin{array}{l}\text { Teachers are expected to assume some responsibility in the early } \\
\text { recognition of pupils' mental health problems. }\end{array}$ & 358 & 90.00 \\
\hline $\begin{array}{l}\text { It is not teachers' job to promote pupils' mental health in the } \\
\text { classroom }\end{array}$ & 100 \\
\hline $\begin{array}{l}\text { Schools hold a unique position in positively affecting the mental } \\
\text { health of pupils. }\end{array}$ & 93.50 \\
\hline $\begin{array}{l}\text { Having pupils with mental health problems in my class impedes the } \\
\text { learning of other pupils. }\end{array}$ & 25.00 \\
\hline
\end{tabular}

Table (5) Teachers' affectiveattitude towardspromoting pupils'mental health $(\mathrm{N}=400)$.

\begin{tabular}{|l|r|r|}
\hline \multicolumn{1}{|c|}{ Statement } & no & \% \\
\hline Promotingpupils'mental health & 377 & 94.25 \\
\hline Recognizingpupils' mentalhealth & 360 & 90.00 \\
\hline Dealingwith pupils'mental health problems inclassroom & 313 & 78.25 \\
\hline Joining a pupilwith mental health problems the class & 167 & 41.75 \\
\hline $\begin{array}{l}\text { Managing a class which includes pupils with mentalhealth problems } \\
\text { makesme feel }\end{array}$ & 72 & 44.25 \\
\hline
\end{tabular}

\section{Table (6) Teachers'behavioral attitude towardspromoting pupils'mental health $(\mathrm{N}=400)$.}

\begin{tabular}{|l|r|r|}
\hline \multicolumn{1}{|c|}{ Statement } & no & \multicolumn{1}{c|}{$\%$} \\
\hline Accepting responsibilityfor promotingpupils' mental healthin classroom. & 358 & 89.50 \\
\hline $\begin{array}{l}\text { Referring the pupil to the mentalhealth professional or the social worker in } \\
\text { the school. }\end{array}$ & 339 & 84.75 \\
\hline Acquiring specifictrainingskills. & 275 & 68.75 \\
\hline $\begin{array}{l}\text { Engage in developing trainingin theappropriate skillstorecognizeand deal } \\
\text { with pupilswith mental healthissues. }\end{array}$ & 274 & 68.50 \\
\hline Suggest to move pupilswith mentalhealth issues from the class. & 267 & 66.75 \\
\hline
\end{tabular}




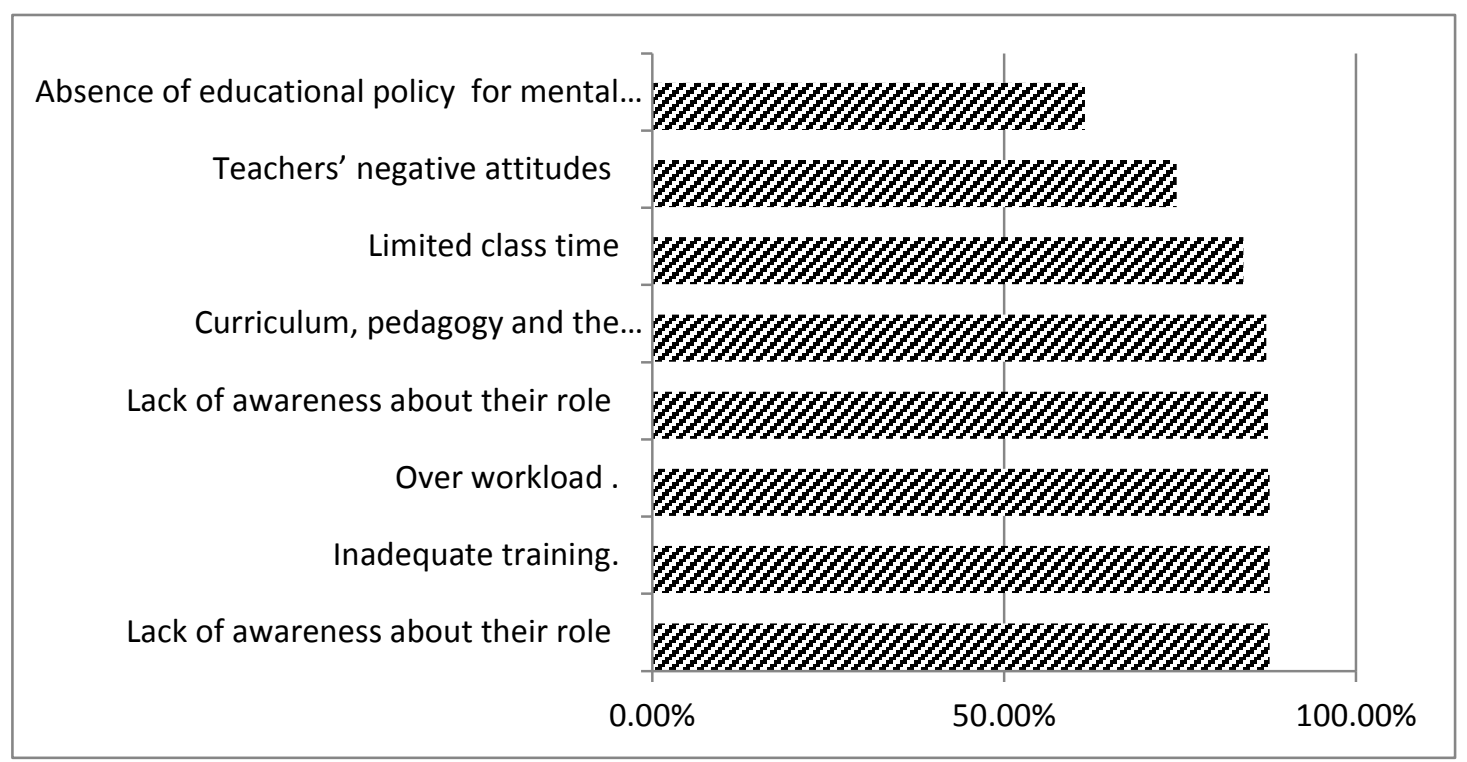

Figure (1) Barriers facing teachers in promoting pupils` mental heal 